Arq. Bras. Med. Vet. Zootec., v.62, n.4, p.973-979, 2010

\title{
Detecção de Listeria monocytogenes pela técnica de PCR em leite contaminado artificialmente
}

[Detection of Listeria monocytogenes by PCR in artificially contaminated milk samples]

\author{
N.D. Peres ${ }^{1}$, C.C. Lange $^{2^{*}}$, M.A.V.P. Brito ${ }^{2}$, J.R.F. Brito ${ }^{2}$, E.F. Arcuri ${ }^{2}$, M.M.O.P. Cerqueira ${ }^{3}$ \\ ${ }^{1}$ Aluno de pós-graduação - EV-UFMG - Belo Horizonte, MG \\ ${ }^{2}$ Embrapa Gado de Leite \\ Rua Eugênio do Nascimento, 610 \\ 36038-330 - Juiz de Fora, MG \\ ${ }^{3}$ Escola de Veterinária - UFMG - Belo Horizonte, MG
}

\begin{abstract}
RESUMO
Avaliou-se a técnica de PCR como opção para reduzir o tempo de detecção de Listeria monocytogenes no leite. Para tanto, amostras de leite desnatado esterilizado e de leite cru integral - com baixa, média e alta contagem de microrganismos aeróbios mesófilos - foram inoculadas experimentalmente com diversas concentrações de L. monocytogenes. Os resultados da reação de PCR foram comparados com os da cultura da amostra empregando-se metodologia padronizada tradicional. Não se detectou $L$. monocytogenes pela reação de PCR quando esta foi realizada a partir do caldo de enriquecimento de Listeria (LEB) após 24 horas de incubação, nem no leite desnatado esterilizado, nem no leite cru integral. Após 48 horas de enriquecimento em LEB, a bactéria foi detectada por PCR nas amostras de leite desnatado esterilizado, com a sensibilidade de $1 \mathrm{UFC} / \mathrm{mL}$, mas não nas amostras de leite cru integral. Pela metodologia tradicional, a bactéria foi recuperada de todos os ensaios. Entretanto, nas amostras de leite cru com altas contagens de aeróbios mesófilos, a sensibilidade da metodologia tradicional foi reduzida (a partir de $7 \mathrm{UFC} / \mathrm{mL}$ ). Melhores resultados foram obtidos quando a reação de PCR foi feita utilizando-se DNA obtido diretamente da colônia suspeita em meio sólido (Oxford e Palcam). Foi possível substituir os testes fenotípicos de identificação de L. monocytogenes pela técnica de PCR reduzindo-se o tempo de identificação da bactéria de vários dias para algumas horas.
\end{abstract}

Palavras-chave: patógeno alimentar, método de detecção, PCR, segurança do leite

\begin{abstract}
The polymerase chain reaction (PCR) was used to detect Listeria monocytogenes in inoculated milk samples after selective enrichment. Samples of sterile skim milk and raw whole milk (with low, intermediate, and high counts of aerobic mesophilic microorganisms) were inoculated with several concentrations of $\mathrm{L}$. monocytogenes. The results of PCR assays were compared to the results of culturing the samples using a standardized traditional method for isolation of L. monocytogenes. The pathogen was detected by PCR in Listeria Enrichment Broth (LEB) after 48h-incubation (sensitivity of $1 C F U / m L$ ) but not after 24h-incubation from the samples prepared with sterile skim milk. L. monocytogenes was not detected by PCR in LEB after 24 and 48h-incubation from the samples prepared with raw whole milk. Using the traditional method, the pathogen was detected in all experiments. However, sensitivity decreased in raw whole milk with high counts of aerobic mesophilic microorganisms (up to 7CFU/mL). Best results were obtained when PCR was done to identify presumptive L. monocytogenes colonies directly from Palcam and Oxford media, after the enrichment step. This procedure allowed reducing to a few hours the period of several days usually needed to obtain the final identification of L. monocytogenes using phenotypic tests.
\end{abstract}

Keywords: food pathogen, detection method, PCR, food safety

Recebido em 23 de março de 2009

Aceito em 12 de julho de 2010

* Autor para correspondência (corresponding author)

E-mail: clange@cnpgl.embrapa.br 


\section{INTRODUÇÃO}

O gênero Listeria compreende seis espécies: $L$. monocytogenes, $L$. innocua, $L$. ivanovii, $L$. seeligeri, L. welshimeri e L. grayi (Liu, 2006). Por resistirem a grandes variações de $\mathrm{pH}$, temperatura e concentrações salinas, as espécies de Listeria estão presentes em ampla variedade de ambientes, incluindo solo, água, efluentes e alimentos (Gandhi e Chikindas, 2007). Somente duas espécies do gênero são consideradas patogênicas, $L$. monocytogenes para o homem e outros animais e $L$. ivanovii para outros mamíferos (Liu, 2006). A doença causada no homem inclui infecções severas, como septicemias, encefalite, meningite e aborto, com altas taxas de hospitalizações e mortes. Acomete principalmente pessoas idosas, recém-nascidos, gestantes e indivíduos imunocomprometidos (Swaminathan, 2001).

Devido à ampla disseminação, capacidade de sobreviver por longos períodos em condições adversas e de se multiplicar em temperaturas de refrigeração $\left(2^{\circ} \mathrm{C}-4^{\circ} \mathrm{C}\right)$, L. monocytogenes tem muitas oportunidades de contaminar o ambiente de produção e processamento de alimentos. Consequentemente, tem sido uma grande preocupação para a indústria alimentícia, pois é responsável por uma significativa proporção das doenças transmitidas por alimentos em todo o mundo (Gandhi e Chikindas, 2007).

Surtos e casos esporádicos de listerioses têm sido relacionados a diferentes tipos de alimentos, como leite, queijos, molhos e derivados cárneos (Swaminathan, 2001). Estudos realizados no Brasil têm comprovado a presença de $L$. monocytogenes no leite (Moura et al., 1993; Silva et al., 2003), queijo (Pimenta et al., 1999; Silva et al., 2003; Maricato et al., 2006; Zaffari et al., 2007) e produtos cárneos (Pimenta et al., 1999; Silva et al., 2004).

Os métodos de diagnóstico tradicionais de isolamento de L. monocytogenes, aprovados por agências regulamentares, requerem vários dias para serem concluídos, pois exigem enriquecimento seletivo, plaqueamento em meios seletivos e confirmação bioquímica dos isolados (Gasanov et al., 2005). O uso de métodos moleculares pode abreviar o tempo de identificação dos métodos tradicionais. A reação de PCR tem sido empregada para detectar $L$. monocytogenes em diferentes tipos de alimentos, incluindo leite e derivados (Starbuck et al., 1992; Fluit et al., 1993; Manzano et al., 1998; Aznar e Alarcón, 2003; Rijpens e Herman, 2004). Nesses estudos, foram relatados sucessos na identificação de $L$. monocytogenes pela amplificação de genes específicos.

Em trabalho anterior, Lange et al. (2005) padronizaram a técnica de PCR para a identificação de L. monocytogenes testando três pares de oligonucleotídeos iniciadores, dois para a amplificação do gene da listeriolisina $\mathrm{O}$ e um para o gene iap (invasion-associated protein). Os melhores resultados foram obtidos com um par de oligonucleotídeos que amplificam o gene da listeriolisina $\mathrm{O}$, o qual se mostrou sensível e específico para L. monocytogenes. O objetivo do presente trabalho foi avaliar a possibilidade de empregar a técnica de PCR para a detecção de $L$. monocytogenes diretamente do caldo de enriquecimento de amostras de leite contaminadas artificialmente com essa bactéria.

\section{MATERIAL E MÉTODOS}

Listeria monocytogenes ATCC 19117 foi usada em toda a fase experimental. A bactéria foi cultivada em caldo BHI (Brain Heart Infusion, Difco) e mantida a $4^{\circ} \mathrm{C}$ com passagens semanais.

A inoculação experimental foi realizada em leite esterilizado e leite cru com diferentes níveis de contaminação. Amostras de leite desnatado foram obtidas após reconstituição de leite em pó desnatado (Molico, Nestlé) de acordo com as recomendações do fabricante, seguindo-se esterilização em autoclave a $110^{\circ} \mathrm{C}$ por 10 minutos. Amostras de leite cru com baixa $\left(10^{3} \mathrm{UFC} / \mathrm{mL}\right)$, média $\left(10^{5} \mathrm{UFC} / \mathrm{mL}\right)$ e alta $\left(10^{7} \mathrm{UFC} / \mathrm{mL}\right)$ contagem total de microrganismos aeróbios mesófilos foram obtidas de rebanhos leiteiros, com história conhecida de baixas, médias e altas contagens no leite, respectivamente.

Inicialmente foi determinada a contagem total de bactérias viáveis de um cultivo de $L$. monocytogenes em $4 \mathrm{~mL}$ de caldo BHI após incubação a $35^{\circ} \mathrm{C}$ por 18 horas. Para isso, diluições decimais da cultura em tampão fosfato foram preparadas e inoculadas em Petrifilm ${ }^{\mathrm{TM}}$ (3M) para contagem de microrganismos aeróbios, em duplicatas. Este procedimento foi repetido três vezes para se obter a contagem 
bacteriana média de uma cultura desta bactéria preparada nestas condições.

A inoculação das amostras de leite foi feita a partir de um cultivo recente da bactéria, preparado como descrito acima. Após a incubação, foram preparadas diluições nas mesmas condições anteriores. O volume de $1 \mathrm{~mL}$ das diferentes diluições foi usado para inocular amostras de $24 \mathrm{~mL}$ de leite. Desse modo, considerando-se a contagem média de $5 \times 10^{8} \mathrm{UFC} / \mathrm{mL}$, esperava-se obter as concentrações de aproximadamente 100, 10, 1 e $0 \mathrm{UFC} / \mathrm{mL}$ no volume final de $25 \mathrm{~mL}$ de leite.

Para cada concentração bacteriana, foram inoculadas três amostras de leite, e uma amostra não inoculada foi utilizada como controle. Após a inoculação das amostras de leite, foi feita a contagem bacteriana total do inóculo, como descrito acima, usando-se Petrifilm ${ }^{\mathrm{TM}}$ para aeróbios, em duplicatas, para determinar o número de $\mathrm{UFC} / \mathrm{mL}$ real do inóculo.

O isolamento de L. monocytogenes foi realizado de acordo com Flowers et al. (1992). Os volumes de $25 \mathrm{~mL}$ de leite, inoculados previamente com diferentes concentrações da bactéria, foram adicionados a $225 \mathrm{~mL}$ de caldo de enriquecimento de Listeria (LEB, Difco), seguindo-se incubação a $30^{\circ} \mathrm{C}$ por 48 horas. A partir do caldo LEB, foram feitos subcultivos em duas placas de ágar Oxford (Difco) e duas de ágar Palcam (Difco). As placas foram incubadas a $35^{\circ} \mathrm{C}$ e examinadas após 24 e 48 horas. Colônias com 2 a $3 \mathrm{~mm}$ de diâmetro, com halos castanhos ou negros, foram selecionadas e repicadas em ágar TSYEA (Ágar triptona extrato de levedura, Difco), de modo a se obter colônias isoladas. As placas de TSYEA foram incubadas a $35^{\circ} \mathrm{C}$ por 24 horas, e as bactérias foram identificadas por meio dos testes bioquímicos: produção de catalase, de oxidase e de hemólise beta, hidrólise da esculina e do hipurato de sódio, teste do Vermelho de Metila e de VogesProskauer, motilidade, CAMP com Staphylococcus aureus e Rhodococcus equi, produção de ácido a partir de glicose, manitol, ramnose, xilose e ribose e redução do nitrato (Lange et al., 2005).

Testes de PCR para detecção de $L$. monocytogenes foram realizados diretamente do caldo LEB, após 24 e 48 horas de incubação, e para a confirmação da identidade das bactérias isoladas, a partir das placas de TSYEA. Para a confirmação da identidade das bactérias, utilizou-se DNA obtido por lise térmica de colônias isoladas, de acordo com $\mathrm{Hu}$ et al. (1999). Para as reações a partir do caldo LEB, foi feita a extração de DNA de $2 \mathrm{~mL}$ da cultura pelos métodos de lise térmica (Nunes et al., 1999) e fenol-clorofórmio (Jersek et al., 1996).

A reação foi realizada em termociclador (GeneAmp PCR System 9600, Applied Biosystems, Foster City, CA, EUA), como descrito por Lange et al. (2005): adicionou-se $1 \mu \mathrm{L}$ de DNA bacteriano $(100 \mathrm{ng} / \mu \mathrm{L})$ a uma mistura contendo $1 \mu \mathrm{L}$ de cada oligonucleotídeo $(10 \mu \mathrm{M}), 5 \mu \mathrm{L}$ de tampão de PCR $10 \mathrm{X}, 1,5 \mu \mathrm{L}$ de $\mathrm{MgCl}_{2}(50 \mathrm{mM}), 1 \mu \mathrm{L}$ da mistura de nucleotídeos (10mM), $1 \mathrm{U}$ de Taq polimerase e água bidestilada para completar um volume de $50 \mu \mathrm{L}$. As condições de amplificação foram: $5 \mathrm{~min}$ a $94^{\circ} \mathrm{C}, 35$ ciclos de 30 s a $94^{\circ} \mathrm{C}, 45 \mathrm{~s}$ a $50^{\circ} \mathrm{C}$ e $45 \mathrm{~s}$ a $72^{\circ} \mathrm{C}$, e uma extensão final de $5 \mathrm{~min}$ a $72^{\circ} \mathrm{C}$. Os oligonucleotídeos utilizados foram LM1/LM2, descritos por Border et al. (1990), os quais amplificam um fragmento de $702 \mathrm{pb}$ do gene hlyA, que codifica a listeriolisina O. Como controle positivo dos testes, usou-se o DNA extraído de L. monocytogenes ATCC 19117, e, como controle negativo, água Milli-Q esterilizada. Os produtos da amplificação foram separados por eletroforese em gel de agarose a $1,5 \%(\mathrm{p} / \mathrm{v})$, corados com brometo de etídio $(0,005 \%, \mathrm{p} / \mathrm{v})$ e fotodocumentados (Eagle Eye II - Stratagene, San Diego, CA, EUA).

\section{RESULTADOS E DISCUSSÃO}

A média das contagens de bactérias viáveis da cultura de L. monocytogenes incubada a $35^{\circ} \mathrm{C}$ por 18 horas foi de $5,0 \times 10^{8} \mathrm{UFC} / \mathrm{mL}$.

A contagem total de bactérias das diferentes amostras de leite é apresentada na Tab. 1. Foram analisadas ao todo 47 amostras de $24 \mathrm{~mL}$ de leite, contaminadas com um número de bactérias viáveis que variou de zero a 1.900UFC. De acordo com a contagem total de aeróbios mesófilos, as amostras de leite cru analisadas foram classificadas em amostras com baixa contagem $\left(2 \times 10^{3} \mathrm{UFC} / \mathrm{mL}\right.$ e $\left.3 \times 10^{3} \mathrm{UFC} / \mathrm{mL}\right)$, contagem média $\left(1,7 \times 10^{5} \mathrm{UFC} / \mathrm{mL}\right)$ e alta contagem $\left(1 \times 10^{7} \mathrm{UFC} / \mathrm{mL}\right.$ e $\left.5 \times 10^{7} \mathrm{UFC} / \mathrm{mL}\right)$. 


\section{Peres et al.}

Tabela 1. Detecção de Listeria monocytogenes pela técnica de PCR diretamente do cultivo em LEB, após 48 horas de incubação, e pela metodologia padronizada convencional a partir de amostras de leite desnatado estéril e leite cru integral

\begin{tabular}{|c|c|c|c|c|c|c|c|c|}
\hline \multirow{2}{*}{$\begin{array}{l}\text { Amostras } \\
\text { de leite }\end{array}$} & \multirow{2}{*}{$\begin{array}{c}\text { Contagem de } \\
\text { microrganismos } \\
\text { aeróbios mesófilos }\end{array}$} & \multirow{2}{*}{$\begin{array}{l}\text { Inóculo de } L \text {. } \\
\text { monocytogenes } \\
\text { (UFC) }\end{array}$} & \multicolumn{3}{|c|}{ Convencional } & \multicolumn{3}{|c|}{ PCR } \\
\hline & & & $\mathrm{A}^{*}$ & B* & $\mathrm{C}^{*}$ & $A^{*}$ & $\mathrm{~B} *$ & $\mathrm{C}^{*}$ \\
\hline \multirow{4}{*}{1} & \multirow{4}{*}{ Leite esterilizado } & 41 & + & + & + & + & + & + \\
\hline & & 4 & + & + & + & + & + & + \\
\hline & & 4 & - & + & - & - & + & - \\
\hline & & 0 & - & - & + & - & - & + \\
\hline \multirow{4}{*}{2} & \multirow{4}{*}{ Leite esterilizado } & 48 & + & + & + & + & + & + \\
\hline & & 4 & + & + & + & + & + & + \\
\hline & & 2 & - & - & + & - & - & + \\
\hline & & 0 & - & - & - & - & - & - \\
\hline \multirow{4}{*}{3} & \multirow{4}{*}{ Leite esterilizado } & 48 & + & + & + & + & + & + \\
\hline & & 8 & + & + & + & + & + & + \\
\hline & & 1 & - & + & - & - & + & - \\
\hline & & 0 & - & - & - & - & - & - \\
\hline \multirow{6}{*}{4} & \multirow{6}{*}{$3 \times 10^{3} \mathrm{UFC} / \mathrm{mL}$} & $600^{\#}$ & + & + & + & - & - & - \\
\hline & & 61 & + & + & + & - & - & - \\
\hline & & 8 & + & + & + & - & - & - \\
\hline & & 2 & - & - & + & - & - & - \\
\hline & & 0 & - & - & - & - & - & - \\
\hline & & 0 & - & - & - & - & - & - \\
\hline \multirow{5}{*}{5} & \multirow{5}{*}{$2 \times 10^{3} \mathrm{UFC} / \mathrm{mL}$} & $450^{\#}$ & + & + & + & - & - & - \\
\hline & & 45 & + & + & + & - & - & - \\
\hline & & 6 & + & + & + & - & - & - \\
\hline & & 0 & - & - & - & - & - & - \\
\hline & & 0 & - & - & - & - & - & - \\
\hline \multirow{5}{*}{6} & \multirow{5}{*}{$1,7 \times 10^{5} \mathrm{UFC} / \mathrm{mL}$} & $350^{\#}$ & + & + & + & - & - & - \\
\hline & & 35 & + & + & + & - & - & - \\
\hline & & 2 & + & + & + & - & - & - \\
\hline & & 0 & - & - & - & - & - & - \\
\hline & & 0 & - & - & - & - & - & - \\
\hline \multirow{7}{*}{7} & \multirow{7}{*}{$1 \times 10^{7} \mathrm{UFC} / \mathrm{mL}$} & $400^{\#}$ & + & + & + & - & - & - \\
\hline & & 40 & + & - & + & - & - & - \\
\hline & & 7 & + & - & + & - & - & - \\
\hline & & 13 & - & - & - & - & - & - \\
\hline & & 1 & - & - & - & - & - & - \\
\hline & & 0 & - & - & - & - & - & - \\
\hline & & 0 & - & - & - & - & - & - \\
\hline \multirow{7}{*}{8} & & $1.900^{\#}$ & + & + & + & - & - & - \\
\hline & & 189 & - & - & + & - & - & - \\
\hline & & 98 & - & - & - & - & - & - \\
\hline & $1 \times 10^{7} \mathrm{UFC} / \mathrm{mL}$ & 45 & - & - & - & - & - & - \\
\hline & & 19 & - & - & - & - & - & - \\
\hline & & 9 & - & - & - & - & - & - \\
\hline & & 0 & - & - & - & - & - & - \\
\hline & & $700^{\#}$ & - & + & + & - & - & - \\
\hline & & 70 & + & + & + & - & - & - \\
\hline 9 & $5 \times 10^{7} \mathrm{UFC} / \mathrm{mL}$ & 8 & - & - & - & - & - & - \\
\hline & & 0 & - & - & - & - & - & - \\
\hline & & 0 & - & - & - & - & - & - \\
\hline
\end{tabular}

*A, B e C: três repetições feitas para cada amostra; ${ }^{\#}$ número estimado de colônias, em decorrência do grande número de colônias no Petrifilm ${ }^{\mathrm{TM}}$; +: positivo após incubação a $30^{\circ} \mathrm{C} / 48$ horas em caldo LEB; -: negativo após incubação a $30^{\circ} \mathrm{C} / 48$ horas em LEB. 
Os resultados da recuperação de $L$. monocytogenes do leite estão apresentados na Tab. 1. Não se detectou L. monocytogenes pela reação de PCR quando esta foi realizada nos cultivos em LEB após 24 horas de incubação, por qualquer um dos métodos usados para extração de DNA. Após 48 horas de enriquecimento em LEB, resultados positivos foram encontrados nas amostras de leite desnatado esterilizado, inoculadas com 1UFC. $\mathrm{Na}$ Fig. 1, mostram-se os produtos de amplificação de $702 \mathrm{pb}$, específicos de $L$. monocytogenes.

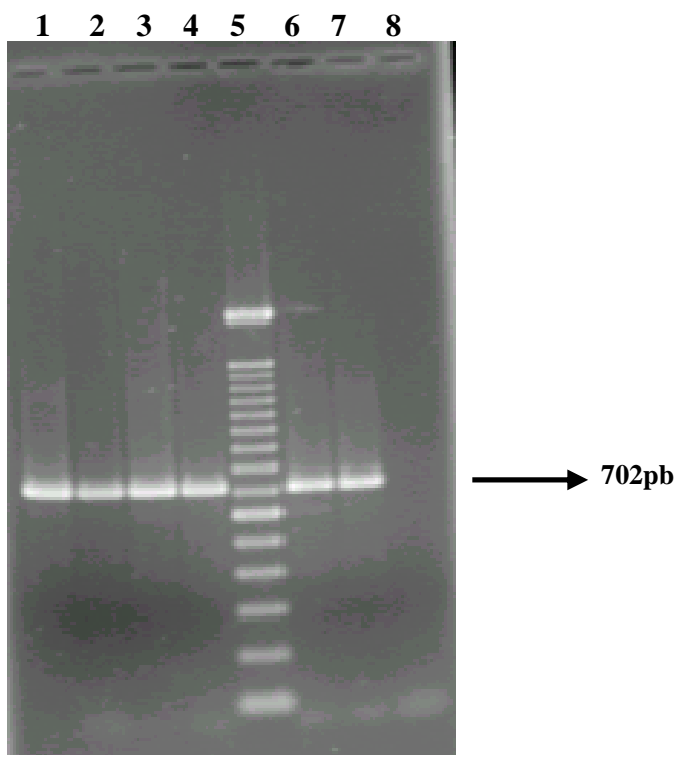

Figura 1. Leite. Reação de PCR com os oligonucleotídeos LM1/LM2, específicos para Listeria monocytogenes. Canaletas 1 a 4, 6 e 7: produtos de amplificação de $702 \mathrm{pb}$. Canaleta 5: marcador de peso molecular de $100 \mathrm{pb}$. Canaleta 8: controle negativo da reação.

Resultados positivos também foram obtidos com a metodologia tradicional, em que se observou crescimento bacteriano nos meios Oxford e Palcam. No ensaio com leite esterilizado, a técnica de PCR e a metodologia tradicional apresentaram a mesma sensibilidade de detecção de L. monocytogenes.

Foram analisadas 16 amostras de leite cru com baixa e média contagem de aeróbios mesófilos, inoculadas experimentalmente, sendo que em seis amostras a contagem de L. monocytogenes no inóculo foi negativa $(0 \mathrm{UFC} / \mathrm{mL})$, e nas demais variou de 2 a $600 \mathrm{UFC} / \mathrm{mL}$. Não foi possível detectar L. monocytogenes por PCR, após 48 horas de enriquecimento em LEB, em nenhuma das concentrações bacterianas inoculadas, independente do método de extração de DNA. Pela metodologia tradicional, foram encontrados resultados positivos nas amostras inoculadas a partir de 2UFC.

De maneira semelhante, também não foi possível detectar L. monocytogenes por PCR após 48 horas de enriquecimento das amostras de leite com alta contagem de aeróbios mesófilos, nem mesmo na amostra inoculada com 1.900UFC. Nesse grupo foram analisadas 19 amostras inoculadas com 1, 7, 8, 9, 13, 19, 40, 45, 70, 98, 189, 400, 700 e 1.900UFC de L. monocytogenes. Verificou-se que a sensibilidade da metodologia tradicional também foi reduzida. Apesar de ter sido possível recuperar a bactéria de amostras inoculadas a partir de 7UFC, não houve recuperação uniforme nas três repetições feitas (Tab. 1).

Aznar e Alarcón (2003) detectaram L. monocytogenes inoculada artificialmente em diferentes alimentos por PCR. A maior sensibilidade da técnica foi obtida com duas etapas de enriquecimento, seguida da purificação do DNA utilizando-se um kit comercial (1 a 10UFC/mL). O aumento da sensibilidade da reação tem sido conseguido por meio de procedimentos que permitem concentrar $\mathrm{o}$ número das bactérias, aumentando a quantidade de DNA disponível ou removendo substâncias que podem ser inibitórias para a reação (Starbuck et al., 1992; Fluit et al., 1993; Rijpens e Herman, 2004). Nogva et al. (2000) usaram PCR quantitativo para detectar L. monocytogenes em leite desnatado e integral não pasteurizado. As reações foram precedidas de separação magnética da bactéria e purificação do DNA. O limite de detecção foi de aproximadamente 6UFC por reação de PCR.

Tem sido relatado que os componentes dos alimentos, dos meios de cultura e dos reagentes utilizados na extração de DNA podem inibir a reação de PCR ou a enzima Taq DNA polimerase, causando decréscimo na sensibilidade da técnica ou até mesmo gerando resultados falso-negativos (Fluit et al., 1993; Manzano et al., 1998; Nogva et al., 2000; Aznar e Alarcón, 2003). Aslam et al. (2003) sugeriram que a gordura do leite poderia cobrir a superfície 
bacteriana e dificultar a lise celular, desse modo diminuiria a sensibilidade da reação de PCR.

A falha na detecção de L. monocytogenes por PCR após 48 horas de enriquecimento nas amostras de leite cru pode também ser devido à presença da microbiota contaminante. Tem sido observado que essa pode interferir com a sua multiplicação (Jiang et al., 1998; Gasanov et al., 2005). Neste caso, redução na multiplicação do patógeno reduziria a quantidade de DNA disponível para a reação.

Dois protocolos diferentes foram usados neste estudo para a extração do DNA bacteriano no meio de enriquecimento empregando-se fenol e clorofórmio e por lise térmica (Jersek et al., 1996; Nunes et al., 1999). No ensaio com leite estéril, foram obtidos produtos de amplificação específicos e nítidos com os dois protocolos. Produtos de PCR a partir de lisado celular de $L$. monocytogenes já foram descritos por outros grupos de pesquisa (Border et al., 1990; Fluit et al., 1993; Aslam et al., 2003; Rijpens e Herman, 2004). A extração por lise térmica é mais rápida, simples (Garcia et al., 2008) e utiliza apenas quantidades pequenas de soluções-tampão, sendo, portanto, mais econômica, oferece menos riscos à saúde do manipulador e causa menos impactos ao meio ambiente. Por esta razão, pode ser usada em substituição à extração por fenol e clorofórmio.

No presente trabalho, melhores resultados foram obtidos quando a reação de PCR foi feita utilizando-se DNA obtido diretamente da colônia suspeita em meio sólido, quando comparado com a reação de PCR feita a partir de alíquotas do cultivo em LEB. Observação semelhante foi feita por Rijpens e Herman (2004) em estudo em que utilizaram PCR para detectar L. monocytogenes em queijos artificialmente contaminados com esse microrganismo. Dessa forma, os resultados deste estudo sugerem a utilização da reação de PCR para identificar o microrganismo isolado em meio seletivo sólido, e não para detectá-lo a partir do caldo de enriquecimento. A identificação por PCR reduz o tempo de identificação da bactéria de vários dias para aproximadamente quatro horas, substituindo uma bateria de testes fenotípicos mais demorados e menos acurados.

\section{CONCLUSÕES}

A técnica de PCR não foi eficiente para a detecção de L. monocytogenes diretamente do caldo de enriquecimento (LEB). Entretanto, foi eficiente para a identificação da bactéria suspeita em meio seletivo (Oxford e Palcam), possibilitando sua identificação definitiva em apenas algumas horas.

\section{AGRADECIMENTOS}

Este trabalho foi conduzido com recursos da FAPEMIG (EDT 2411/05) e Embrapa (Prodetab 047-02/99). Nádia David Peres foi bolsista da CAPES.

\section{REFERÊNCIAS BIBLIOGRÁFICAS}

ASLAM, M.; HOGAN, J.; SMITH, K.L. Development of a PCR-based assay to detect Shiga toxin-producing Escherichia coli, Listeria monocytogenes, and Salmonella in milk. Food Microbiol., v.20, p.345-350, 2003.

AZNAR, R.; ALARCÓN, B. PCR detection of Listeria monocytogenes: a study of multiple factors affecting sensitivity. J. Appl. Microbiol., v.95, p.958-966, 2003.

BORDER, P.M.; HOWARD, J.J.; PLASTOW, G.S. et al. Detection of Listeria species and Listeria monocytogenes using polymerase chain reaction. Lett. Appl. Microbiol., v.11, p.158-162, 1990.

FLOWERS, R.S.; ANDREWS, W.; DONNELLY, C.W et al. Pathogens in milk and milk products. In: MARSHALL, R.T. (Ed.). Standard methods for the examination of dairy products. 16.ed. Washington: APHA, 1992. Chap.5. p.103-212.

FLUIT, A.C.; TORENSMA, R.; VISSER, M.J.C. et al. Detection of Listeria monocytogenes in cheese with the magnetic immuno-polymerase chain reaction assay. Appl. Environ. Microbiol., v.59, p.1289-1293, 1993.

GANDHI, M.; CHIKINDAS, M.L. Listeria: A foodborne pathogen that knows how to survive. Int. J. Food Microbiol., v.113, p.1-15, 2007. 
GARCIA, P.M.; ARCURI, E.F. BRITO, M.A.V.P. et al. Detecção de Escherichia coli 0157:H7 inoculada experimentalmente em amostras de leite cru por método convencional e PCR multiplex. Arq. Bras. Med. Vet. Zootec., v.60, p.1241-1249, 2008.

GASANOV, U.; HUGHES, D.; HANSBRO, P.M. Methods for the isolation and identification of Listeria spp. and Listeria monocytogenes: a review. FEMS Microbiol. Rev., v.29, p.851-875, 2005.

HU, Y.; ZHANG, Q.; MEITZLER, J.C. Rapid and sensitive detection of Escherichia coli O157:H7 in bovine faeces by a multiplex PCR. $J$. Appl. Microbiol., v.87, p.867-876, 1999.

JERSEK, B.; TCHERNEVA, E.; RIJPENS, N. et al. L. Repetitive element sequence-based PCR for species and strain discrimination in the genus Listeria. Lett. Appl. Microbiol., v.23, p.55-60, 1996.

JIANG, J.; LARKIN, C.; STEELE, M. et al. Evaluation of universal preenrichment broth for the recovery of foodborne pathogens from milk and cheese. J. Dairy Sci., v.81, p.2798-2803, 1998.

LANGE, C.; PERES, N.D.; ARCURI, E.F. et al. Identificação de Listeria monocytogenes pela reação em cadeia da polimerase. Rev. Inst. Cândido Tostes, v.60, p.150-153, 2005.

LIU, D. Identification, subtyping and virulence determination of Listeria monocytogenes, an important fodborne pathogen. J. Med. Microbiol., v.55, p.645-659, 2006.

MANZANO, M.; COCOLIN, L.; CANTONI, C. et al. A rapid method for the identification and partial serotyping of Listeria monocytogenes in food by PCR and restriction enzyme analysis. Int. J. Food Microbiol., v.42, p.207-212, 1998.

MARICATO, E.; ARCURI, E.F.; LANGE, C. et al. Prevalência sazonal de patógenos de origem alimentar de amostras de leite pasteurizado e queijo Minas frescal comercializadas em Juiz de Fora, Brasil. Rev. Inst. Cândido Tostes, v.61, p.207-210, 2006.

MOURA, S.M.; DESTRO, M.T.; FRANCO, B.D.G.M. Incidence of Listeria species in raw and pasteurized milk produced in São Paulo, Brazil. Int. J. Food Microbiol., v.19, p.229-239, 1993.
NOGVA, H.K.; RUDI, K.; NATERSTAD, K. et al. Application of 5'-nuclease PCR for quantitative detection of Listeria monocytogenes in pure cultures, water, skim milk, and unpasteurized whole milk. Appl. Environ. Microbiol., v.66, p.4266-4271, 2000.

NUNES, E.L.C.; SANTOS, K.R.N.; MONDINO, P.J.J. et al. Detection of ileS-2 gene encoding mupirocin resistance in methicillinresistant Staphylococcus aureus by multiplex PCR. Diag. Microbiol. Infect. Dis., v.34, p.7781, 1999.

PIMENTA, F.C.; FURLANETTO, S.M.P.; MAYER, L.W. et al. Molecular characterization of Listeria monocytogenes isolated from foods. Rev. Microbiol., v.30, p.356-361, 1999.

RIJPENS, N.; HERMAN, L. Comparison of selective and nonselective primary enrichments for the detection of Listeria monocytogenes in cheese. J. Food Microbiol., v.94, p.15-22, 2004.

SILVA, I.M.M.; ALMEIDA, R.C.C.; ALVES, M.A.O. et al. Occurrence of Listeria spp. in critical control points and the environment of Minas Frescal cheese processing. Int. J. Food Microbiol., v.81, p.241-248, 2003.

SILVA, W.P.; LIMA, A.S.; GANDRA, E.A. et al. Listeria spp. no processamento de linguiça frescal em frigoríficos de Pelotas, RS, Brasil. Cienc. Rural, v.34, p.911-916, 2004.

STARBUCK, M.A.B.; HILL, P.J.; STEWART, G.S.A.B. Ultra sensitive detection of Listeria monocytogenes in milk by the polymerase chain reaction (PCR). Lett. Appl. Microbiol., v.15, p.248-252, 1992.

SWAMINATHAN, B. Listeria monocytogenes. In: DOYLE, M.P.; BEUCHAT, L.R.; MONTVILLE, T.J. (Eds). Food microbiology: fundamentals and frontiers. Washington: ASM, 2001. p.383-409.

ZAFFARI, C.B; MELLO, J.F.; COSTA, M. Qualidade bacteriológica de queijos artesanais comercializados em estradas do litoral norte do Rio Grande do Sul, Brasil. Cienc. Rural, v.37, p.862-867, 2007. 